\title{
ANALISIS SALURAN PEMASARAN MAKANAN RINGAN KEDELAI CRISPY (Studi Kasus di Desa Bendasari Kecamatan Sadananya Kabupaten Ciamis)
}

\author{
IIS MULYATI ${ }^{1}$, DINI ROCHDIANI ${ }^{2}$, BUDI SETIA ${ }^{\mathbf{1}}$ \\ ${ }^{1}$ Fakultas Pertanian Universitas Galuh \\ ${ }^{2}$ Fakultas Pertanian Universitas Padjadjaran
}

\begin{abstract}
ABSTRAK
Penelitian ini bertujuan untuk mengetahui : (1) Saluran pemasaran kedelai crispy di Desa Bendasari Kecamatan Sadananya Kabupaten Ciamis, (2) Besarnya biaya, marjin dan keuntungan pemasaran dari lembaga pemasaran kedelai crispy di Desa Bendasari Kecamatan Sadananya Kabupaten Ciamis, (3) besarnya bagian harga yang diterima pengusaha (share) dari harga yang dibayarkan konsumen.

Jenis penelitian yang digunakan adalah metode survai, dengan mengambil kasus di Desa Bendasari Kecamatan Sadananya Kabupaten Ciamis. Teknik pengambilan sampel dilakukan dengan metode acak sederhana (Purposive Sampling). Responden yang diambil sebanyak 1 orang yang ada di daerah penelitian, sedangkan sampel untuk lembaga pemasaran diambil dengan cara (Snowball Sampling) terhadap 1 orang pedagang pengecer. Hasil penelitian menunjukkan bahwa :
\end{abstract}

1) Terdapat dua saluran pemasaran kedelai crispy di Desa Bendasari Kecamatan Sadananya Kabupaten Ciamis. Pada saluran pemasaran 1: perajin $\rightarrow$ konsumen akhir. Pada saluran pemasaran 2: perajin $\rightarrow$ pedagangpengecer $\rightarrow \quad$ konsumen akhir.

2) Pada saluran 2 pemasaran kedelai crispy melibatkan satu lembaga pemasaran yaitu pedagang pengecer. Besarnya total marjin pada saluran pemasaran II adalah Rp. 4.500,00 per kg dengan total biaya pemasaran sebesar Rp.47.78 per kg sehingga total keuntungan pemasaran sebesar Rp. 4.453 per kg.

3) Besarnya bagian harga yang diterima perajin (share) pada saluran 1 adalah 100 persen, sedangkan pada saluran II adalah 89,54 persen.

Kata kunci : Pemasaran, Kedelai, Perajin.

\section{PENDAHULUAN}

Pembangunan pertanian dapat didefinisikan sebagai suatu proses perubahan sosial. Implementasinya tidak hanya ditujukan untuk meningkatkan status dan kesejahteraan petani semata, tetapi sekaligus juga dimaksudkan untuk mengembangkan potensi sumberdaya manusia baik secara ekonomi, sosial, politik, budaya, lingkungan, maupun melalui perbaikan (improvement), pertumbuhan (growth) dan perubahan (change) (Iqbal dan Sudaryanto, 2008).
Di Indonesia kedelai merupakan komoditi tanaman pangan yang amat penting dan strategis dalam ekonomi nasional, karena memiliki peran pokok sebagai pemenuh kebutuhan pangan, pakan dan industri dalam negeri yang setiap tahunnya cenderung meningkat. Kedelai merupakan komoditas pertanian yang mempunyai kandungan unsur gizi yang tinggi sehingga layak untuk dikonsumsi manusia. Permintaan yang meningkat tersebut terutama didorong oleh meningkatnya industri tahu, kecap dan 
pakan. Kekurangan bahan mentah kedelai akan terus meningkat dimasa yang akan datang (Adisarwanto, 2008).

Kedelai Crispy adalah salah satu jenis makanan yang terbuat dari kedelai yang mana kedelainya diolah. Kedelai Crispy ini dapat kita jumpai di sekeliling kita. Proses pembuatannya membutuhkan waktu lumayan lama. Pembuatan Kedelai Crispy ini tidaklepasdari kriteria bahan yang dibutuhkan makadari itu bahan yang dipilih hatus baik,agar kedelai crispydihasilan baik. (Setiawan, 2013)

Pemasaran aspek yang harus dikaji, mengenai saluran pemasaran belum diperoleh informasi sehingga perlu dikaji, sehubungan dengan latar belakang tersebut, maka penulis tertarik untuk melaksanakan penelitian mengenai "Analisis Saluran Pemasaran Makanan Ringan Kedelai Crispy" yang merupakan studi kasus pada seorang perajin makanan ringan kedelai crispy di Desa Bendasari Kecamatan Ciamis Kabupaten Ciamis.

\section{METODE PENELITIAN}

\section{Jenis Penelitian}

Jenis penelitian yan digunakan adalah studi kasus dengan mengambil kasus di Desa Bendasari Kecamatan Sadananya Kabupaten Ciamis,Studi kasus adalah penelitian tentang status subjek penelitian berkenaan pada suatu fase spesifik. Subjek penelitian dapat saja individu , kelompok, lembaga maupun masyarakat.(Nazir,2011)

\section{Teknik Pengumpulan Data}

Data yang akan dikumpulkan dalam penelitian ini berasal dari data primer dan data sekunder. Data primer diambil dengan cara observasi dan wawancara langsung kepada pimpinan dan karyawan Kedelai crispy, wawancara dilakukan dengan menggunakan pertanyaan (questionary), sedangkan Data sekunder diperoleh dari, desa, BPP, dan studi literatur yang relevan.

\section{Teknik Penarikan Responden}

Desa Bendasari Kecamatan Sadananya ditentukan secara (purposive sampling).

\section{Rancangan Analisis Data}

Untuk mengetahui pola saluran pemasaran kedelai crispy di Desa Bendasari Kecamatan Sadananya Kabupaten Ciamis digunakan analisis secara deskriptif.

1) Saluran pemasaran kedelai crispy akan dianalisis secara deskriptif dengan menggambarkan pola atau saluran pemasaran kedelai crispy di 
Desa Bendasari Kecamatan

Sadananya Kabupaten Ciamis.

2) Untuk mengetahui biaya pemasaran, maka digunakan rumus sebagai berikut (Angipora, 2010).

$\mathrm{TC}=\mathrm{MP}-\pi$

Keterangan :

MP : Marjin pemasaran di lembaga pemasaran

$\Pi \quad$ :Keuntungan ditingkat lembaga pemasaran

TC :Total biaya pemasaran ditingkat lembaga pemasaran

3) Marjin pemasaran adalah selisih harga tingkat produsen dan tingkat konsumen akhir. Secara matematis rumus umum marjin pemasaran dirumuskan sebagai berikut (Ulya , 2007) dalam (Singarimbun, 2013):

$\mathrm{M}=\mathrm{Pr}-\mathrm{Pf}$

Marjin yang diperoleh pedagang perantara dari sejumlah biaya pemasaran yang dikeluarkan dan keuntungan yang diterima oleh pedagang perantara dirumuskan sebagai berikut:

$\mathrm{M}=\mathrm{Bp}+\mathrm{Kp}$

Keterangan:

Pr : Harga di tingkat konsumen

Pf : Harga di tingkat produsen

M : Marjin pemasaran

Kp : Keuntungan pemasaran
Bp : Biaya pemasaran

4) Keuntungan pemasaran dihitung dengan rumus sebagai berikut (Hanafie , 2010) :

$\mathrm{Kp}=\mathrm{M}-\mathrm{JB}$

Keterangan :

Kp : Keuntungan Pemasaran

JB : Jumlah Biaya

M : Marjin

5) Share merupakan indikator lain untuk membandingkan antara harga yang diterima perajin dengan harga yang dibayarkan oleh konsumen akhir dinyatakan dalam persentase (Angipora, 2010). Share dapat dirumuskan sebagai berikut:

$\mathrm{S}=\frac{\mathrm{P}}{\mathrm{K}} \times 100 \%$

Keterangan:

S : Share

$\mathrm{P} \quad$ : Harga di tingkat perajin

K : Harga yang dibayarkan

oleh konsumen

\section{HASIL DAN PEMBAHASAN}

\section{Identitas responden}

Data yang ada meliputi umur,pendidikan, pengalaman berusaha dan jumlah tanggungan keluarga. 


\section{Umur}

Faktor usia dapat mempengaruhi terhadap keberhasilan dalam melajukan suatu kegiatan usaha, Berdasarkan hasil penelitian diperoleh data usia responden antara 30 tahun sampai 46 tahun.

\section{Pendidikan}

Tingkat pendidikan peranannya cukup tinggi terhadap seseorang dalam melakukan kegiatan usaha, karena tingkat pendidikan dapat mempengaruhi seseorang dalam menerima dan melaksanakan hal-hal yang baru.

\section{Jumlah Tanggugan Keluarga}

Mata pencaharian penduduk Desa Bendasari cukup beragam, dan sebagian besar bekerja sebagai wiraswasta karena Desa Bendasari merupakan daerah agroindustri dimana sebagian penduduknya bermata pencaharian sebagai wiraswasta.

\section{Pengalaman Berusaha Responden}

Pengalaman berusaha merupakan faktor yang sangat menentukan keberhasilan dalam usaha agroindustri tempe, semakin lama pengalaman usaha maka akan semakin tinggi keterampilan yang dimiliki dalam melakukan proses produksi.

\section{Tanggungan Keluarga Responden}

Keluarga yang menjadi tanggungan dalam hal ini adalah anggota keluarga atau sanak saudara yang tinggal satu rumah dengan dan bergantung hidup kepadanya.

\section{Saluran Pemasaran Makanan Ringan}

\section{Kedelai Crispy}

Saluran pemasaran kedelai crispy merupakan suatu jalur yang dilalui oleh arus barang dari perajin ke perantara dan akhirnya sampai kepada pemakai atau konsumen. Lembaga pemasaran yang terlibat dalam pemasaran kedelai crispy dari perajin sampai ke tangan konsumen akhir adalah pedagang pengecer.

\section{Saluran Pemasaran di Tingkat Peraji.}

Perajin menjual ke konsumen dan dipasarkan ke pedagang pengecer. Produk yang akan dipasarkan sudah dikemas plastik oleh perajin dengan label perusahaan. Proses pemasarannya yaitu produk diambil langsung oleh pedagang pengecer dan ada juga konsumen datang langsung untuk membeli produk. Harga jual kedelai crispy pada saluran 1 di tingkat perajin sebesar Rp. 38.500,- per $\mathrm{kg}$, dan harga jual pada saluran 2 sebesar Rp. 43.000,- per kg dengan sistem pembayaran tunai. 
Tabel 1. Rata-rata Biaya Pemasaran kedelai crispy di Desa Bendasari.

\begin{tabular}{llrr}
\hline No. & Jenis Biaya & $\mathbf{R} / \mathbf{K g}$ & $\begin{array}{c}\text { Sersentase } \\
(\boldsymbol{\%})\end{array}$ \\
\hline 1 & Retribusi & 5,56 & 11,64 \\
2 & Bongkar Muat & 33,33 & 69,76 \\
3 & Transportasi & 8,89 & 18,60 \\
Total & & 47,78 & 100,00 \\
\hline
\end{tabular}

Tabel 2. Rata-rata Biaya, Marjin dan Keuntungan Pemasaran Makanan Ringan Kedelai Crispy

\begin{tabular}{lrr}
\hline \multicolumn{1}{c}{$\begin{array}{c}\text { Lembaga } \\
\text { Pemasaran }\end{array}$} & $\begin{array}{c}\text { Margin } \\
(\mathbf{R p} / \mathbf{K g})\end{array}$ & \multicolumn{1}{c}{$\begin{array}{c}\text { Persentase } \\
(\boldsymbol{\%})\end{array}$} \\
\hline Perajin & & \\
Harga Perajin & 38.500 & 89,66 \\
Harga jual & 43.000 & 100 \\
Konsumen & & \\
Harga beli & 43.000 & 100 \\
Margin & 4.500 & 10,07 \\
Pemasaran & & \\
\hline
\end{tabular}

Tabel 3. Rata-rata Biaya, Marjin dan Keuntungan Pemasaran Makanan Ringan Kedelai Crispy pada Saluran 2 di Desa Bendasari

\begin{tabular}{lrr}
\hline \multicolumn{1}{c}{$\begin{array}{c}\text { Lembaga } \\
\text { Pemasaran }\end{array}$} & $\begin{array}{c}\text { Margin } \\
(\mathbf{R p} / \mathbf{K g})\end{array}$ & \multicolumn{1}{c}{$\begin{array}{c}\text { Persentase } \\
(\boldsymbol{\%})\end{array}$} \\
\hline $\begin{array}{l}\text { Perajin } \\
\text { Harga jual }\end{array}$ & 38.500 & 89,66 \\
Pedagang Pengecer & & \\
Harga beli & 38.500 & 89,66 \\
Harga jual & 43.000 & 100 \\
Total biaya & 47.78 & 1,18 \\
pemasaran & & \\
- Retribusi & 5,56 & 0,24 \\
- Bongkar Muat & 33,33 & 0,57 \\
- Transportasi & 8.89 & 0,37 \\
Margin & 4.500 & 10,34 \\
Pemasaran & & \\
Margin & 3.987 & 9,17 \\
Keuntungan & & \\
Konsumen & & 100 \\
$\begin{array}{l}\text { Harga beli } \\
\text { Total Biaya }\end{array}$ & 43.000 & 100 \\
$\begin{array}{l}\text { Pemasaran } \\
\text { Total Margin }\end{array}$ & & \\
$\begin{array}{l}\text { Pemasaran } \\
\text { Total Margin } \\
\text { keuntungan }\end{array}$ & 4.500 & 10,34 \\
\hline
\end{tabular}

\section{Share Perajin}

Share Perajinadalah analisis yang digunakan untuk mengetahui bagian harga yang diterima oleh perajin dengan cara membandingkan antara harga di tingkat perajin dengan harga yang dibayar oleh konsumen.

Berdasarkan hasil penelitian menunjukkan bahwa harga jual di tingkat perajin adalah Rp.43.000 per kg. Harga kedelai crispy pada saluran I Rp. 43.000 per kg, maka besarnya nilai Share perajinpada saluran 1 adalah:

$$
\begin{aligned}
\text { Share } & =\frac{\mathrm{Pf}}{\mathrm{Pr}} \times 100 \\
& =\frac{43.000}{43.000} \times 100 \\
& =100 \%
\end{aligned}
$$

Harga jual kedelai crispy di perajin pada saluran II Rp. 38.500 per $\mathrm{kg}$ dan harga jual di pedagang pengecer Rp.43.000 per $\mathrm{kg}$, maka besarnya nilai Share Perajinpada saluran 2 adalah:

$$
\begin{aligned}
\text { Share } & =\frac{\mathrm{Hp}}{\mathrm{He}} \times 100 \% \\
& =\frac{38.500}{43.000} \times 100 \% \\
& =89,54 \%
\end{aligned}
$$

Berdasarkan hasil perhitungan diketahui bahwa nilai Share pada saluran I sebesar 100 persen dan pada saluran II sebesar 89,54 persen. 


\section{KESIMPULAN DAN SARAN}

\section{Kesimpulan}

Berdasarkan hasil pembahasan

yang telah diuraikan serta memperhatikan tujuan penelitian yang telah ditetapkan, maka diperoleh kesimpulan sebagai berikut

1. Terdapat dua saluran pemasaran kedelai crispy dari perajin sampai ke tangan konsumen akhir yaitu :

\section{Saluran Pemasaran I Salu}

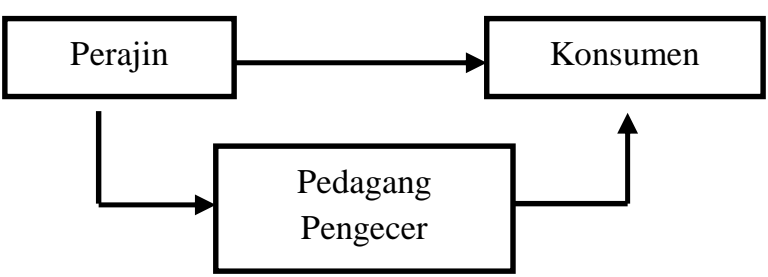

2. Pada saluran I pemasaran kedelai crispy melibatkan satu lembaga pemasaran yaitu pedagang pengecer. Besarnya total marjin pada saluran pemasaran II adalah Rp. 4.500,00 per $\mathrm{kg}$ dengan total biaya pemasaran $\mathrm{Rp}$. 47.78,- per $\mathrm{kg}$ sehingga total keuntungan pemasaran Rp. 4.453,00 per kg. Besarnya bagian harga yang diterima perajin

3. Besarnya bagian harga yang diterima saluran I (share) adalah 100 persen dan saluran II 89,54 persen.

\section{Saran}

Berdasarkan hasil dari pembahasan dan kesimpulan, maka dapat direkomendasikan kepada perajin kedelai crispy di Desa Bendasari Kecamatan Sadananya Kabupaten Ciamis yang ingin meningkatkan pendapatannya sebaiknya perajin kedelai crispy harus lebih aktif mencari peluang pasar. Perajin juga harus memperluas pemasaran dengan cara promosi baik melalui media cetak atau menggunakan sosial media karena cara ini dianggap efektif agar produk semakin dikenal luas.

\section{DAFTAR PUSTAKA}

Adisarwanto, T. 2008. Budidaya Kedelai Tropika. Penebar Swadaya. Jakarta. Angipora. 2010. Dasar-dasar Pemasaran. Raja Grafindo Persada. Jakarta

Hanafie, R. 2010. Pengantar Ekonomi Pertanian. CV Andi Offserlt. Yogyakarta.

Iqbal, M, Sudaryanto, T. 2008. Tanggung Jawab Sosial Perusahaan (Corporate Social Responsibility) dalam Perspektif Kebijakan Pembangunan Pertanian. Analisis Kebijakan Pertanian, vol. 6 No. 2, Juni 2008.

Stanton, william J.2007. Prinsip Pemasaran yang dikutip oleh Dharmesta Jakarta; Erlangga. 